\title{
Nature reserve group planning for conservation of giant pandas in North Minshan, China
}

\author{
Jing Xiao ${ }^{a}$, Weihua $\mathrm{Xu}^{\mathrm{b}}$, Dongwei Kang ${ }^{\mathrm{a}}$, Junqing $\mathrm{Li}^{\mathrm{a}, *}$ \\ a The Key Laboratory for Silviculture and Conservation of Ministry of Education, Beijing Forestry University, Beijing 100083, China \\ ${ }^{\mathrm{b}}$ State Key Laboratory of Urban and Regional Ecology, Research Centre for Eco-Environmental Sciences, Chinese Academy of Sciences, Beijing 100085, China
}

\section{A R T I C L E I N F O}

\section{Article history:}

Received 19 July 2010

Received in revised form 9 January 2011

Accepted 16 January 2011

\section{Keywords:}

Connectivity

Core areas

Functional zoning

Giant panda

Habitat evaluation

Least cost analysis

Nature reserve groups

\begin{abstract}
A B S T R A C T
Formation of nature reserve groups (NRGs) is an important approach for optimising spatial patterns in nature reserves and for improving the efficiency of nature reserve networks. In this study, based on habitat evaluation and connectivity analysis, the approach and method for optimising spatial patterns and functional zoning of reserves were analysed using the case study of giant panda (Ailuropoda melanoleuca) reserves in North Minshan. Results indicated that five panda nature reserves had been established, which formed a reserve group and covered $48.4 \%$ of panda habitat and three of five population components. Although the nature reserves were connected to each other, core zones were divided into seven isolated areas. These divisions can reduce the efficiency of protecting giant pandas in reserve systems. To optimise spatial patterns in nature reserves, one new reserve is proposed and it is recommended that core zones be expanded and merged into two areas, in accordance with the spatial distribution of the panda population. Three linkage areas are also proposed-for facilitating panda exchange and movement among different populations. The study is expected to provide a scientific basis for planning the development of nature reserves in this mountain range, to promote the establishment of nature reserve groups in other areas, and to optimise entire nature reserve systems in China.
\end{abstract}

(c) 2011 Elsevier GmbH. All rights reserved.

\section{Introduction}

The establishment of nature reserves is regarded as one of the most effective means of conserving biodiversity (Richard et al. 2010). By the end of 2009, 2538 nature reserves had been established in China, covering 1.47 million $\mathrm{km}^{2}$, or $14.7 \%$ of China's land surface (Ministry of Environmental Protection 2010). During the early stages of the establishment of these nature reserves, however, an emergency style of conservation planning was adopted that was not fully informed by on-the-ground field assessments. This system lacked integrated planning; as much land as possible was designated for conservation of threatened species, after which the nature reserves were established on an ad hoc (or 'step-bystep') basis. The spatial patterns of nature reserves were therefore not always appropriate for conservation; nature reserves were isolated from each other and formed isolated conservation 'islands'. Although some area-limited species may be well-conserved in single-isolated reserves, many species of conservation concern could be placed at risk of extinction in such systems when isolation promotes genetic drift and loss of genetic diversity (Hill \&

\footnotetext{
* Corresponding author. Tel.: +86 (10)62338100.

E-mail address: lijq@bjfu.edu.cn (J. Li).
}

Curran 2003). When habitat connectivity is the ultimate goal, spatial pattern greatly impacts the overall efficiency of nature reserve systems (Kunin 1997). For this reason, appropriate spatial planning is a high priority for the establishment of China's nature reserves (Wan 2006).

The establishment of nature reserve groups (NRGs) in key areas for biodiversity conservation is one of the main approaches for solving problems associated with spatial isolation of 'conserved islands' and to improve the efficacy of nature reserve networks (Zhang \& Zheng 2008). Some NRGs have been formed, or are being planned, on the basis of multi-species distribution (Xiao et al. 2004) or flagship species distribution (Wang et al. 2009; Xu et al. 2006) at the scale of mountain range or even provincial scale (Zhang \& Zheng 2008).

Although nature reserves in such groups are often connected with each other, ecosystems contained within the reserves are still at risk of fragmentation via discontinuities in the functional zoning system. In the early 1990s, the Chinese government mandated that all nature reserves be divided into three functional zones: core; buffer; and, experimental in order to allow for multiuse planning (The State Council 1994). The core zones are the most concentrated areas for the conservation of target species or regions (for example, endangered species or important ecosystems) and receive the most stringent protection. Experimental 


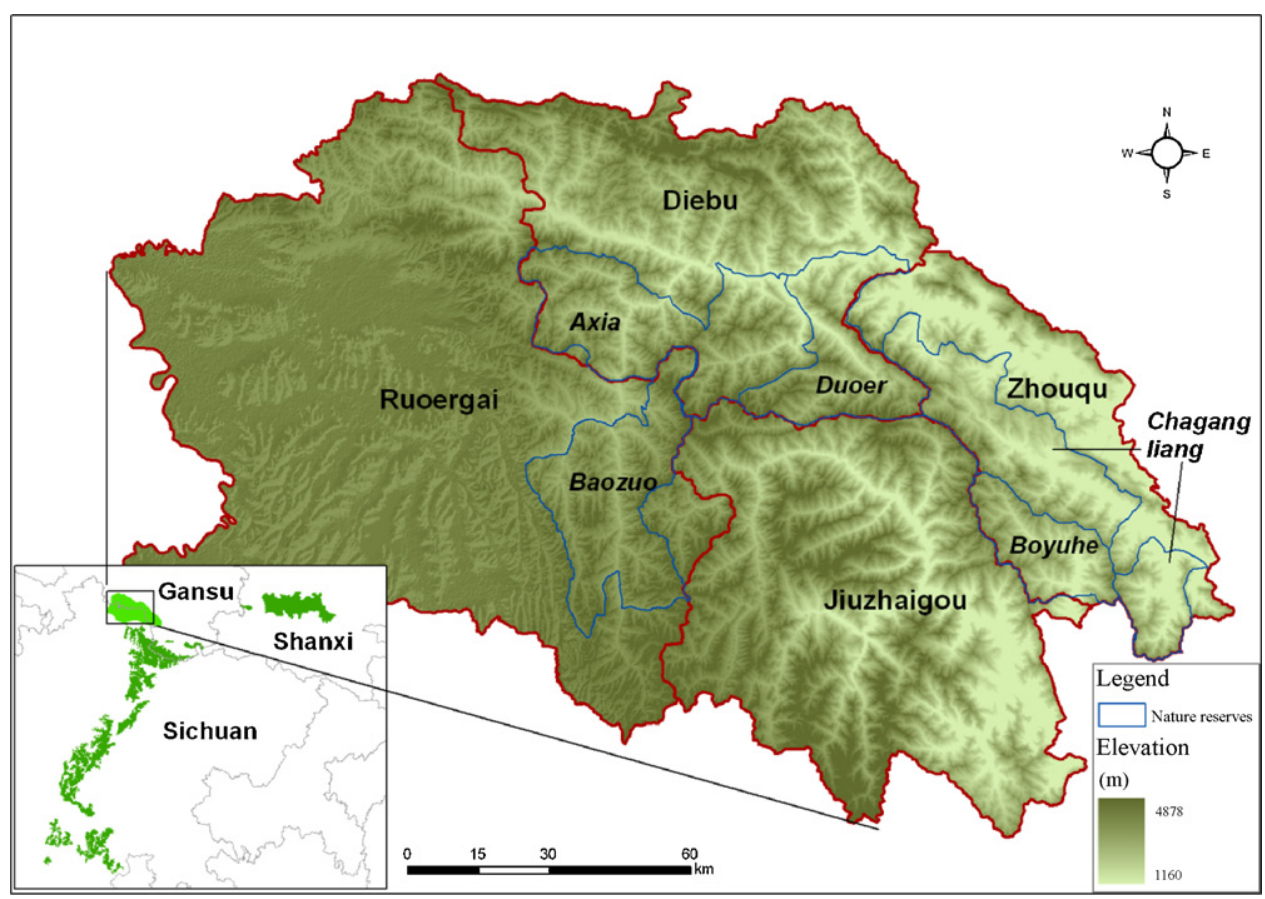

Fig. 1. Location of study area in the entire panda distribution area (shown in the lower left corner).

zones are areas that constitute suitable habitats for endangered species but can and in some cases currently are being used for exploitation (for example, tourism infrastructure: The State Council 1994). Buffer zones are areas that mitigate the impacts on the core zones of human activities occurring in the experimental zones. Zoning boundaries typically are designed by considering a combination of factors including natural terrain features, vegetation types, observed and hypothesised animal distributions, and existing human establishments (Liu \& Li 2008). However, zoning designations have historically lacked a sound scientific underpinning and in many instances are drawn up with little available data and with a lack of integrative framework in which to weigh competing characteristics (Liu \& Li 2008). Perhaps one of the most challenging issues arising from the functional zoning system when considering cross-boundary effects among neighbouring reserves is that discontinuities between core zones - caused by human disturbances in experimental zones - can significantly decrease the efficacy of NRGs. Thus, the connectivity between core zones of nature reserves should be given a high priority when designing NRGs.

The Minshan Mountain Range is in the southwest of China, in one of the 25 biodiversity hotspots (Myers et al. 2000). North Minshan is one of the main conservation areas for the endangered giant panda. The population in this area was previously called the 'Minshan Population C', which is separated from other populations, referred to as 'Minshan Population A' and 'Minshan Population B' (State Forestry Administration 2006). Since 2003, five nature reserves with connected boundaries have been established to conserve the giant panda and its habitat. These nature reserves were, however, designed mainly on the basis of individual reserves and core zones were not connected. Isolation of core zones could threaten the long-term survival of wild giant pandas in this area. The present study examines the optimal design features of NRGs, on the basis of habitat assessment and cost-distance analysis, for the purpose of maintaining the long-term survival of panda in this area. Specific objectives are as follows: (1) assessing habitat fragmentation in the study area; (2) analysing connectivity status using cost-distance analysis; and, (3) designing NRGs and functional zones.

\section{Study area}

This study was carried out in North Minshan, which includes two counties (Zhouqu and Diebu) in Gansu Province and two counties (Ruoergai and Jiuzhaigou) in Sichuan Province, and covers an area of about $31,470 \mathrm{~km}^{2}$ (Fig. 1). Elevation is low in the east and high in the west, ranging from 1160 to $4878 \mathrm{~m}$. There are seven major vegetation gradients in the study area, comprising the following types (occurring, sequentially, from low to high elevation): shrubs; evergreen broad-leaved forest; evergreen and deciduous broad-leaved mixed forest; deciduous broad-leaved forest; broadleaved and coniferous mixed forest; subalpine coniferous forest; and, alpine shrubs and subalpine meadows ( $\mathrm{Hu} 2001$ ).

This area is important for the conservation of giant pandas in Minshan. According to the third national survey of the giant panda and its habitat (State Forestry Administration 2006), this area (defined as 'Minshan C') contains a population of about 30 individuals, which is isolated from the population at 'Minshan A' (in the middle region) and that at 'Minshan $B$ ' (in the southern region). For the conservation of giant panda and its habitat, five provincial nature reserves have been established since 2003. Among them, Baozuo is in Sichuan, and the three other reserves (Axia, Duoer, Chagangliang, and Boyuhe) are in Gansu Province. Besides giant pandas, this area is also the home of many other endangered or key protected species, including Snow Leopard (Uncia uncia), and Golden Monkey (Rhinopithecus roxellanae), Chinese Yew (Taxus chinensis) (Hu 2001).

\section{Method}

Habitat assessment

Panda habitat in the study area was assessed using a conceptual model (Liu et al. 1999; Xu et al. 2006), according to which suit- 
able habitat is determined by requiring that it meets a number of criteria based on the biological requirements of giant pandas: (1) classified as forest cover type; (2) between $1200 \mathrm{~m}$ and $3800 \mathrm{~m}$ elevation; and (3) less than $50^{\circ}$ slope. A number of procedures were followed in order to compile a final habitat map. Landcover data were from image classification based on Landsat TM with a resolution of $30 \mathrm{~m} \times 30 \mathrm{~m}$, acquired from September 18, 2007, provided by China Remote Sensing Satellite Ground Station. This image was classified as 'forest' and 'non-forest', using supervised classification with a classification accuracy of $86 \%$. Slope and elevation data were from a Digital Elevation Model (DEM) with a resolution of $30 \mathrm{~m} \times 30 \mathrm{~m}$, provided by the National Geomatics Center of China. Detailed information about the habitat assessment can be obtained from Xu et al. (2006) and Liu et al. (1999).

\section{Cost-distance analysis}

Connectivity of panda habitats was analysed by means of calculating least cost analysis (Liu \& Li 2008). The source layer and resistance layer were the two main aspects of a cost-distance calculation. Source layer was identified according to the distribution of the panda population and its habitat. As noted in the third national survey, panda populations in the study area were isolated into five groups, and the five distribution areas were accordingly defined as the source layers. Pandas need to overcome resistance against movement between sources and these resistance factors include biotic factors (i.e. land cover and bamboo), abiotic factors (e.g. elevation, slope and aspect), and human activities (e.g. distance from residential areas and roads).

A GIS analysis was undertaken using ArcGIS 9.3. Six factors were selected and the resistance for each factor was divided into three or four classes, from high to low resistance values (Table 1 ) according to the recommendations of Shen et al. (2008) and Liu and Li (2008) as well as results from research on giant pandas (Hu 2001; Liu et al. 1999; Wang et al. 2009; Xu et al. 2006). As was the case for the habitat assessment, vegetation type was based on image classification and data was obtained from the following sources: slope and elevation from a DEM; and residential and road data from the National Geomatics Center of China. The overall resistance value was the summation of the six individual resistance values, which was further used for calculating the cumulative cost of movement between each of the five sources.

In order to identify high connectivity paths between different resources, least cost analysis was carried out between every possible combination of two sources (from the total of five sources) using the "corridor" function in ArcGIS 9.3. This analysis produces the range of cumulative costs between any two sources (ESRI 2007). The range was reclassified into 100 classes with equal areas (i.e. 1\% of the total area for each class). Class 1 had the lowest cumulative cost and highest connectivity, and class 100 had the highest cumulative cost and lowest connectivity. This analysis was iteratively carried out for each pair of two of the five sources, producing 10 connectivity layers. The final overall connectivity map depicted the configuration of reserves that yielded the minimum resistance value after summing the individual resistance values from the 10 layers.

\section{Conservation planning for giant panda reserve groups}

Based on habitat assessment and cost-distance analysis, three aspects of conservation planning were considered: identification of key areas for new nature reserves; adjustment of functional zones for NRGs; and identification of linkage areas. Key areas should contain a large amount of suitable habitat, large panda populations, high connectivity between panda groups, and minimal human disturbance. Adjustment of functional zones of nature reserve groups should be based on least cost analysis and basic patterns of 'core zones-buffer' and 'zones-experimental zones' (Xu \& Bao 2004). Source areas and areas with low cumulative costs and low human disturbance between source areas should be contained in the core zone; areas with strong human activities and disturbances should be contained in the experimental zone; and the buffer zone should contain those areas around experimental zones assessed on the basis of resistance analysis. Linkage areas should be identified in areas with high connectivity (i.e. low cumulative costs) between different panda population sources.

\section{Results}

\section{Habitat distribution and fragmentation}

The total area of giant panda habitat in North Minshan is about $5285 \mathrm{~km}^{2}$, distributed in zones surrounded by national road 213 (G213), provincial road 313 (S313), and provincial road S301 (Fig. 2). A road connecting national road 213 and provincial road S301 and the associated human activities, are the major factors causing habitat fragmentation in this area.

\section{Conservation status}

Current nature reserves in North Minshan cover $2558 \mathrm{~km}^{2}$ of panda habitat, which represents $48.4 \%$ of the total habitat in this area (Fig. 2). Current nature reserves only protect the panda populations in A, B and E, but no protection is available in C and D (Fig. 3). Although the nature reserves are connected to each other, the core zones are isolated into seven areas (Fig. 3). These spatial relationships decrease the conservation efficiency of the NRGs with respect to protecting giant pandas.

\section{Least cost analysis and nature reserve group planning}

The cumulative costs between each pair of two of the five sources are illustrated in Fig. 4, which indicates the relative connectivity between sources. According to this analysis, there are two main migration corridors connecting sources. One is $\mathrm{C} 11$, connecting sources $B$ and $E$ through $A$ in the north, and the other is C12, connecting sources B and E through C and D in the south. In addition, four minor migration corridors including C21 to C24 are also important for connecting sources $\mathrm{A}$ and $\mathrm{B}, \mathrm{A}$ and $\mathrm{C}$, and $\mathrm{A}$ and D.

By overlapping the layers corresponding to nature reserves, the panda habitat, and the panda population, one key area was identified in the remaining habitat outside of current nature reserves (Fig. 5). This was located in north Jiuzhaigou County and the eastern region of Nuoergai County and covers a large area of suitable habitat with an area of $1704 \mathrm{~km}^{2}$ and two isolated panda populations.

Functional zones were also planned within reserves and key areas. Two core zones existed for the nature reserves network, containing sources A, D, E in the north, and B and C in the south, respectively. Most of the high connectivity areas between sources were also in the core zones. Buffer zones were surrounded by experimental zones, which were designated as human disturbance areas (for example, for roads and residential plots).

Three linkage areas were also identified based on least cost analysis and migration corridors. These areas included a road crossing between S301 and G213 and mainly distributed in experimental zones, the three areas connecting sources $A$ and $B, A$ and $C$, and $C$ and D, respectively (Fig. 5). 
Table 1

The resistance of various biological and abiotic factors.

\begin{tabular}{|c|c|c|c|c|c|c|c|c|c|c|c|}
\hline \multicolumn{2}{|l|}{ The 1 st factors } & \multicolumn{2}{|l|}{ The 2nd factors } & \multicolumn{2}{|c|}{ The 3rd factors } & \multicolumn{2}{|c|}{ The 4th factors } & \multicolumn{2}{|c|}{ The 5th factors } & \multicolumn{2}{|c|}{ The 6th factors } \\
\hline Vegetation type & RRV & Elevation (m) & RRV & Slope $\left({ }^{\circ}\right)$ & RRV & $\mathrm{DMD}(\mathrm{m})$ & RRV & $\mathrm{DSD}(\mathrm{m})$ & RRV & $\mathrm{DRA}(\mathrm{m})$ & RRV \\
\hline Forest & 1 & $1500-3100$ & 1 & $<20$ & 1 & $>720$ & 1 & $>90$ & 1 & $>1920$ & 1 \\
\hline Shrub & 50 & $1200-1500,3100-3300$ & 10 & $20-35$ & 10 & $720-210$ & 10 & $30-90$ & 10 & $1410-1920$ & 10 \\
\hline Meadow, agricultural land & 90 & $<1200,3300-3800$ & 50 & $35-45$ & 50 & $210-60$ & 50 & $<30$ & 100 & $900-1410$ & 50 \\
\hline Water, residential areas & 100 & $>3800$ & 100 & $>45$ & 100 & $<60$ & 100 & - & & $<900$ & 100 \\
\hline
\end{tabular}

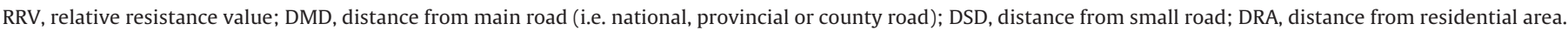

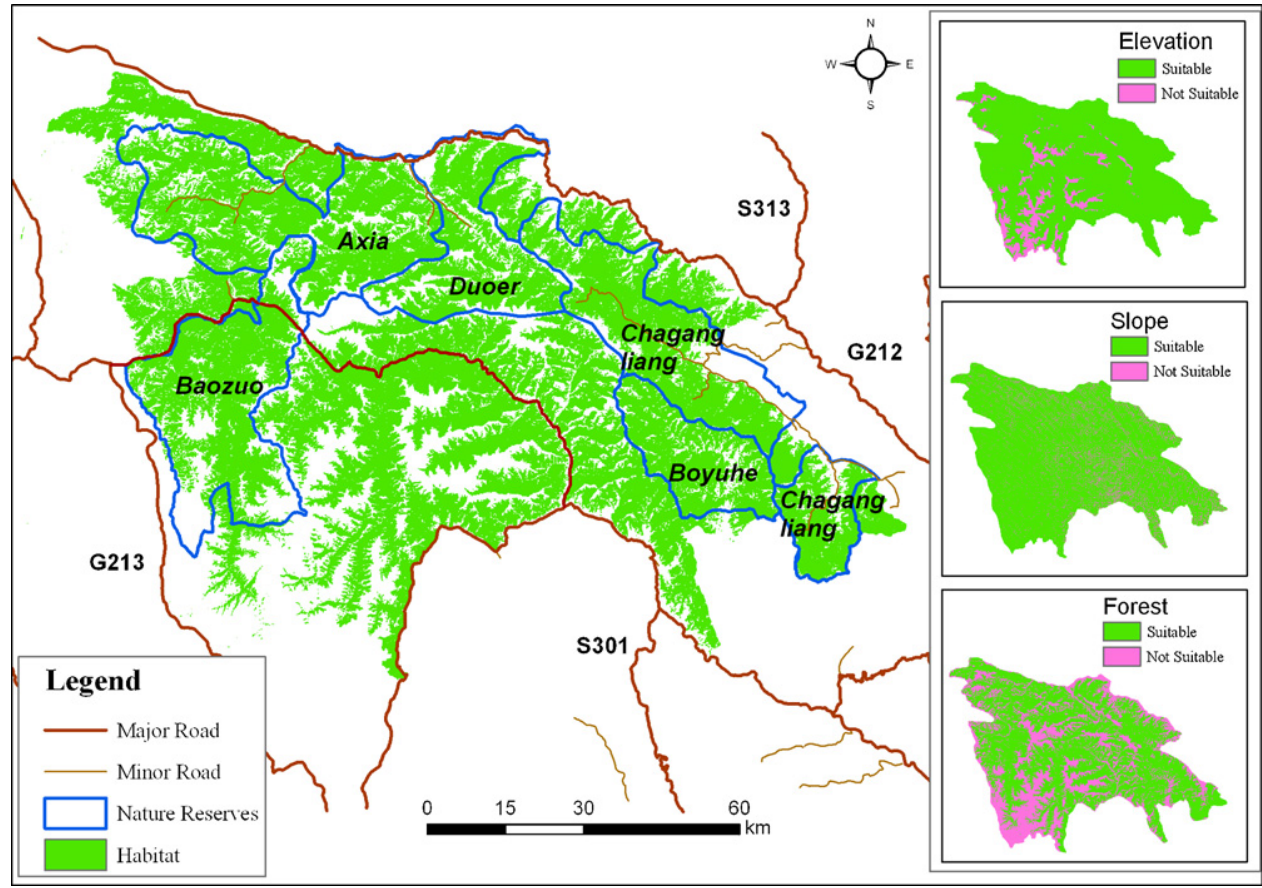

Fig. 2. Distribution of panda habitat in North Minshan.

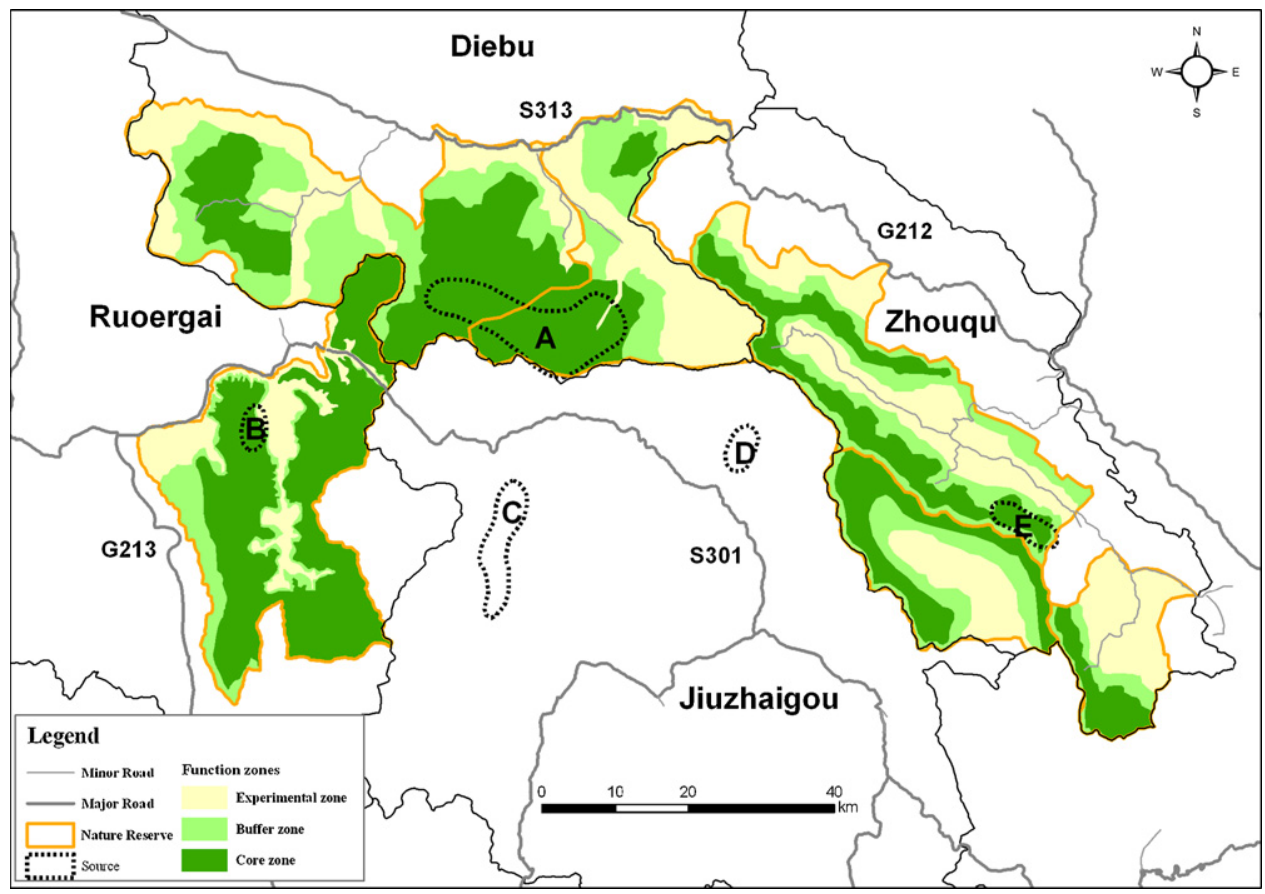

Fig. 3. Functional zones of nature reserves in North Minshan. 


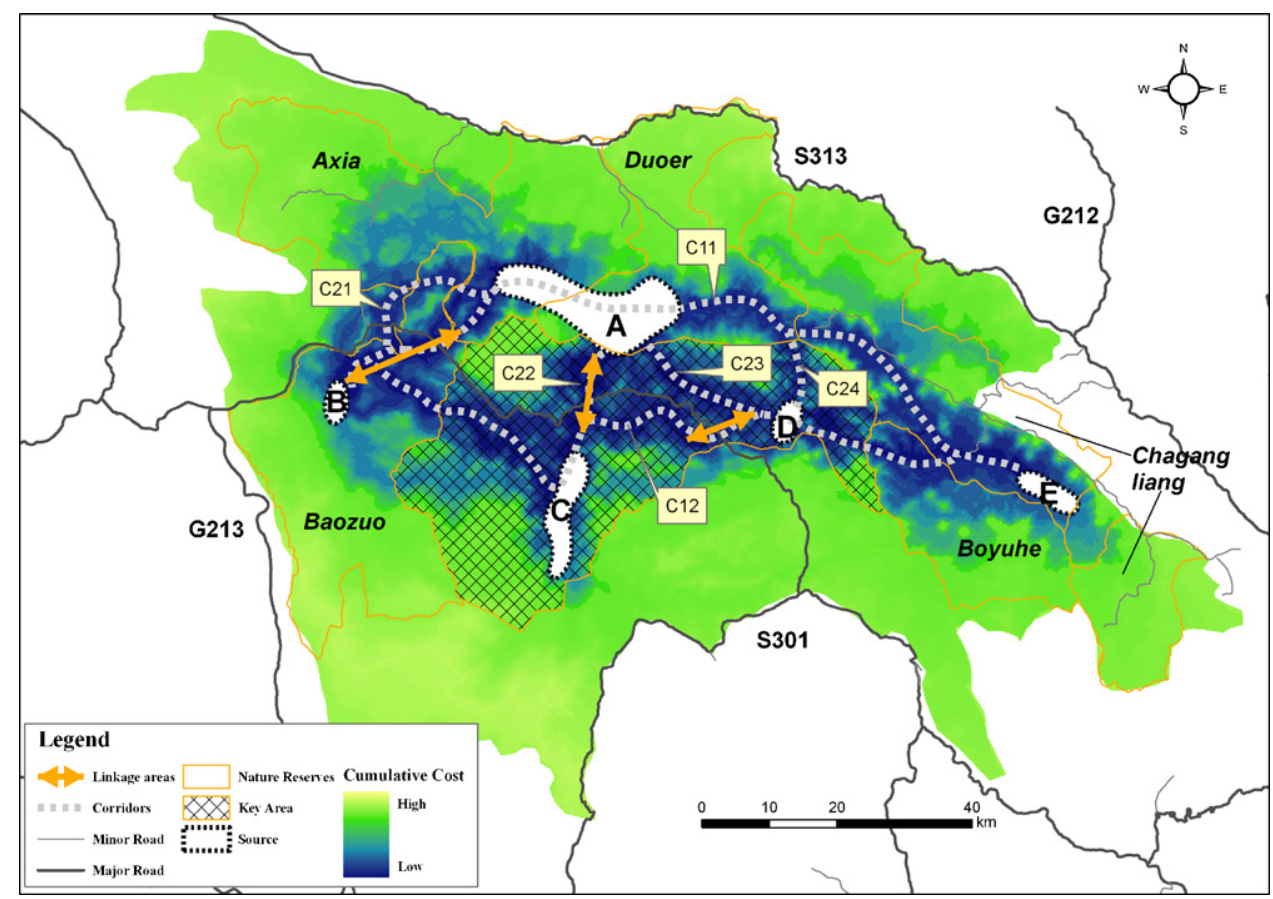

Fig. 4. Least cost analysis for giant panda habitat in North Minshan.

\section{Discussion}

Isolation due to habitat loss and human activities in areas surrounding nature reserves is a significant challenge for biodiversity conservation worldwide (Margules \& Pressey 2000). This factor has the potential to reduce the conservation capacity of reserves for protecting biodiversity, even if habitat is maintained within the reserves (DeFries et al. 2005). In this study area, the total population size of wild giant pandas was about 30 , but the population was distributed among five different groups potentially isolated by the road between G213 and S301 and the surrounding residential plots. Current nature reserves cover $48.4 \%$ of the panda habitat in this study area, but only cover three of the five panda population groups. Although the three groups were protected within core zones in each nature reserve, the core zones were separated by buffer zones and experimental zones, where human disturbance is officially allowed. This separation may increase the probability of extinction of the panda population in the future, considering that previous studies have hypothesised that panda populations consisting of 10 or fewer

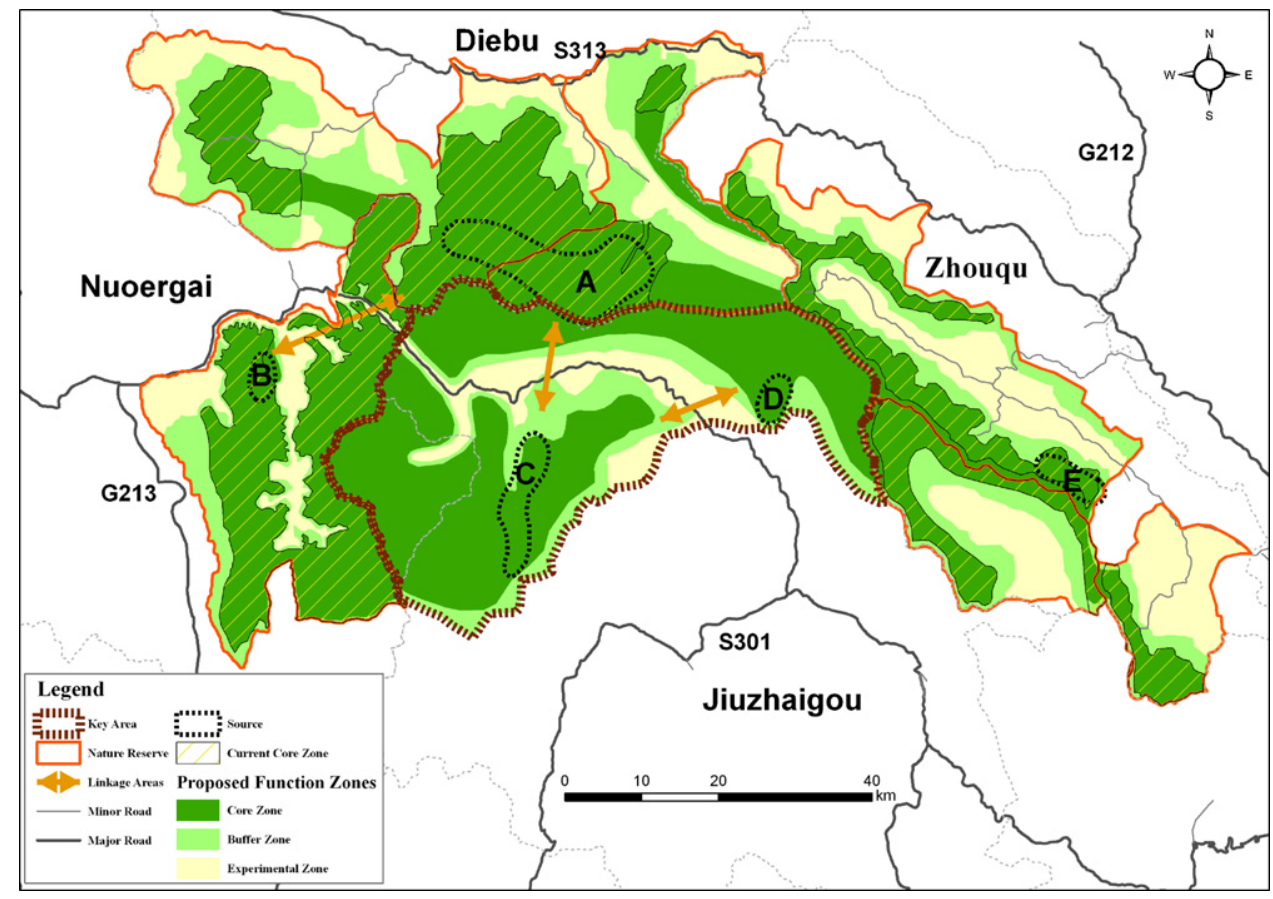

Fig. 5. Proposed design of the nature reserve group (NRG) in North Minshan. 
individuals have an extinction probability of $41 \%$ (Wang et al. 2002).

Current and future human activities may threaten the long-term survival of the giant panda and its habitat in this area. Currently, threats from human activities mainly consist of transportation along the road between G213 and S301 and tourism in the southern part of Jiuzhai County. But threats in the future may increase, considering that a railway between Chengdu and Gansu will be established and running through this area by the end of 2014 (Chengdu Government Website 2009). Although most of railway running through this area will be underground, construction of this railway will inevitably affect panda habitat because there will likely be a rapid increase of human activities (e.g. tourism) resulting from the railway and other transportation infrastructure. These threats may increase the current degree of isolation of panda habitat and may further affect pandas' survival in the long run. There is, thus, an urgent need to expand the nature reserves and to adjust functional zones so as to connect isolated core zones where human development is not allowed.

Habitat protection in the key areas and linkage areas proposed in this study should be carried out to ensure the sustainability of the giant panda population and its habitat in this area. Nature reserves should be established in the key area considering that this area contains a large area of habitat, two panda population groups, and critical migration corridors between different population groups spanning the entire North Minshan region. Proper protection measures should also be taken for the three linkage areas which cross the major road between G213 and S301, and other human activities in the experimental areas. Possible measures include habitat restoration and transportation control during winter and spring in such areas, as this will encourage the exchange of pandas between different population groups. In addition, further survey and analysis should be carried out to promote functional zone adjustment of reserves on the basis of the current study. To maximise efficiency of the overall protection scheme, such measures should be carried out across the entire area or at the level of nature reserve groups, rather than at the level of individual reserves.

Some of China's recent environmental policies could potentially aid in the formation and operation of the type of conservation planning proposed in this study. One group of policies concerns conservation payment programs in China. Conservation payments have recently been distributed by the central government in the counties of fifty national key ecological service areas, amounting to tens of billions of RMB each year (Ministry of Finance People's Republic of China 2009). Future provision of such services is dependent upon evaluations of the changes in environmental conditions in the county of interest. While this Minshan study area currently encompasses several counties participating in the conservation payment programs, future provision of funds is not guaranteed, but could be encouraged by improvements of ecosystems and species habitat under a more effective reserve design like the one we propose here.

Another policy framework that is pertinent to mention here relates to both local and national-level conservation planning overhauls that are currently underway in China, which could conceivably include nature reserve networks designed in the same way we have done here. At the local level, planning projects such as the post-Zhouqu Landslides disaster restoration and reconstruction plan are currently being implemented by the Central government (TCPGPRC 2010). At the national level, the coming 10-year (2011-2020) plan for conservation of the giant panda and its habitat in China is a major undertaking that should ideally be founded on sound nature reserve design principles. Under this framework, conservation planning of the type proposed in this study area could be realised and converted to on-the-ground management and even be replicated across the entire giant panda habitat in order to tackle significant challenges relating to habitat isolation across what are increasingly complex human-influenced systems.

\section{Acknowledgements}

This research was supported by the project for the preponderant disciplines innovation platform for Beijing Forestry University and The National Key Technology Research and Development Program (2008BADB0B04). We thank the Administration of Gansu Forestry Administration for providing species data and nature reserves maps, and two anonymous reviewers as well as Vanessa Hull for their constructive and helpful comments and suggestions.

\section{References}

Chengdu Government Website. (2009). Establishment of railway between Chengdu and Lanzhou. (in Chinese). http://www.chengdu.gov.cn/harmonious chengdu/detail.jsp?id=241144

DeFries, R., Hansen, A. J., Turner, B. L. I. I., Reid, R., \& Liu, J. (2005). Land use change around protected areas: Management opportunities to balance human needs and ecological function. Ecological Applications, 15(1), 19-26.

ESRI. (2007). ArcInfo ${ }^{\circledR} 9$ using ArcGIS desktop.

Hill, J. L., \& Curran, P. J. (2003). Area, shape and isolation of tropical forest fragments: Effects on tree species diversity and implications for conservation. Journal of Biogeography, 30(9), 1391-1403.

Hu, J. (2001). Research on the giant panda. Shanghai: Shanghai Science \& Technology Education Press. (in Chinese).

Kunin, W. E. (1997). Sample shape, spatial scale and species counts: Implications for reserve design. Biological Conservation, 82(3), 369-377.

Liu, X. H., \& Li, J. H. (2008). Scientific solutions for the functional zoning of nature reserves in China. Ecological Modeling, 215(1-3), 237-246.

Liu, J., Ouyang, Z., Yang, Z., Taylor, W., Groop, R., Tan, Y., et al. (1999). A framework for evaluating the effects of human factors on wildlife habitat: The case of giant pandas. Conservation Biology, 13(6), 1360-1370.

Margules, C. R., \& Pressey, R. L. (2000). Systematic conservation planning. Nature, 405, 243-253.

Ministry of Environmental Protection, P.R. China. (2010). Construction and management status of nature reserves in China in 2009. http://sts.mep.gov.cn/ zrbhq/zrbhqgzjb/201006/t20100604_190513.htm

Ministry of Finance People's Republic of China. (2009). Methods of transfer payment in national key ecological services areas. (in Chinese). http://yss.mof.gov.cn/ zhengwuxinxi/zhengceguizhang/200912/t20091225_252633.html

Myers, N., Mittermeier, R. A., Mittermeier, C. G., da Fonseca, G. A. B., \& Kent, J. (2000) Biodiversity hotspots for conservation priorities. Nature, 403, 853-858.

Richard, A. F., Eve, M., Kerrie, A. W., Josie, C., Hedley, S. G., James, E. M. W., et al (2010). Replacing underperforming protected areas achieves better conservation outcomes. Nature (advance online publication: 30 June 2010).

Shen, G. Z., Feng, C. Y., Xie, Z. Q., Ouyang, Z. Y., Li, J. Q., \& Pascal, M. (2008). Proposed conservation landscape for giant pandas in the Minshan mountains, China. Conservation Biology, 22(5), 1144-1153.

State Forestry Administration P.R.C. (2006). Report of the third national giant panda census. Beijing, China: Science Publishing House. (in Chinese).

The Central People's Government of the People's Republic of China. (2010). Overall planning of post Zhouqu Landslides disaster restoration and reconstruction. (in Chinese). http://www.gov.cn/zwgk/2010-11/10/content_1742124.htm

The State Council. (1994). Bylaws of nature reserves in the People's Republic of China. (in Chinese).

Wan, B. T. (2006). Retrospection and expectation of China's nature reserves development. Environmental Protection, 21, 21-25 (in Chinese).

Wang, H., Li, S. G., \& Pan, W. S. (2002). Population viability analysis of giant panda (Ailuropoda melanoleuca) in Qinling Mountains. Acta Scientiarum Naturalium Universitatis Pekinensis, 38, 756-761.

Wang, X. Z., Xu, W., \& Ouyang, Z. Y. (2009). Integrating population size analysis into habitat suitability assessment: Implications for giant panda conservation in the Minshan Mountains, China. Ecological Research, 24, 1101-1109.

Xiao, Y., Ouyang, Z. Y., Zhu, C. Q., Zhao, J. Z., He, G. J., \& Wang, X. K. (2004). An assessment of giant panda habitat in Min Mountain, Sichuan, China. Acta Ecologica Sinica, 24(7), 1373-1379 (in Chinese).

Xu, H. G., \& Bao, H. S. (2004). On the methods of ecological security design for nature reserves. Chinese Journal of Applied Ecology, 15(7), 1266-1270 (in Chinese).

Xu, W. H., Ouyang, Z. Y., Vina, A., Zheng, H., Liu, J. G., \& Xiao, Y. (2006). Designing a conservation plan for protecting the habitat for giant pandas in the Qiongla mountain range, China. Diversity and Distributions, 12, 610-619.

Zhang, Y. M., \& Zheng, D. X. (2008). A framework study on the construction of terrestrial biodiversity conservation network. Journal of Subtropical Resources and Environment, 3(2), 1-10 (in Chinese). 